\title{
A Technique for Improving the Radar Visibility of Search and Rescue Transponder Responses
}

\author{
Richard M. Trim OBE
}

(Gilden Research Ltd.)

I. ReView of proposed technique. The Search And Rescue Transponder (SART) forms the essential final homing element of the Global Marine Distress and Safety System (GMDSs). When interrogated by a marine $\mathrm{x}$-band navigation radar, it transmits a sequence of twelve cycles, during which its reply frequency is swept rapidly back and forth across the entire marine $3 \mathrm{~cm}$ frequency band (9200-9500 Mhz). As the SART reply frequency sweeps repeatedly through the pass band of the observing radar, a sequence of dots appears on the radar display, originating approximately at the relative range and bearing of the SART-equipped vessel (e.g. life-raft). This enables radar-equipped vessels to home onto the life-raft in order to effect a rescue.

In relatively calm weather, with a correspondingly smooth sea surface, the system works well and a number of rescues have been assisted by its use. However, under conditions where the surface of the sea is roughened, the radar echoes from the sea surface (sea clutter) may obscure the SART replies, especially at short range, reducing the effectiveness of SART as a final homing aid. Since the SART reply transmission sweeps across the band of frequencies used by commercial marine navigation radars, whereas any given radar will only receive signals close to the centre frequency to which it is tuned, the possibility exists of tuning the receiver such that echoes from its own transmissions are not received, whereas signals from a SART will be.

On the face of it, this is a simple and economic solution that is easy to arrange. Unfortunately, as is so often the case in marine electronics, the position is not as straightforward as it might seem.

2. IMPLEMENTATION. The main problem arises from the fact that, in the case of most modern commercial marine navigation radars, the receiver cannot be sufficiently de-tuned as to remove sea clutter echoes from the display, especially when the radar is operating on its shorter range scales (narrow transmitted pulse, wide bandwidth). Indeed, some modern marine radars have automatic frequency control (AFC), taking the tuning of the receiver out of the hands of the operator. Even where manual tuning is provided, the tuning range is often so restricted as to prevent a situation arising where, possibly unnoticed by the operator, radar echoes of navigational significance are not displayed.

The implication is that, for such a receiver-centre frequency-tuning provision to be implemented, the design of radars currently being manufactured would have to be changed and radars already in use modified.

Previously, the cost involved in either course of action has been regarded, in the costconscious marine electronics market, as unacceptable to end customers (ship-owners and operators). However, in the experience of this author, this prejudice has been more in the minds of the marine radar manufacturers than their customers, little effort having been made by the former to convince the latter of the advantages of such facilities, whose cost is, in any case, quite small.

A further technical difficulty which may be encountered, if the radar receiver is detuned unnecessarily far from its normal condition, is that of frequency-sensitive radar antenna squint which arises with the end-fed slotted waveguide (swG) antennas almost 
universally used for commercial marine navigation radars, of typically I degree per $100 \mathrm{MHz}$ frequency change at $\mathrm{x}$-band. However, this is unlikely to affect the visibility of SART transmissions at ranges at which obscuration due to sea clutter is likely to be a problem.

3. CONCLUSION. In conclusion, it is recommended that serious consideration be given by the marine community to the provision of a frequency off-set facility in commercial, $\mathrm{x}$-band marine navigation radars, in order to improve the radar visibility of replies from Search And Rescue Transponders (SART), which otherwise might be obscured by echoes from sea clutter.

\title{
KEY WORDS
}

I. Radar. 2. Search and rescue. 3. Transponders.

\section{'A Voyage of Navigational Investigation'}

\author{
From W. G. L. Randles
}

The paper by Michael Richey in the September 1995 issue of the Journal ${ }^{1}$ raises a number of points which underline a general divergence of views between historians and practical seamen concerning the use or otherwise of nautical astronomy in early Portuguese voyages. However, I should start by acknowledging that Richey's account of the content of my Imago Mundi paper $^{2}$ is very fair and strictly impartial.

The problem, as I see it, turns upon the difficulty of communication between professional historians and professional seamen. The historian, as I see it, can only speak about what he finds in dated documents and this was the point of view of distinguished Portuguese historians like Luís de Albuquerque and Damião Peres. Portuguese seamen such as Commander Fontoura da Costa, Commander Moreira Campos and Commander Estácio dos Reis have argued and do argue that their nautical experience demands that the Azores, whose presence appears on early dated charts, could only have been reached and returned to, using some form of nautical astronomy.

Gabriel Valsequa's Majorcan chart of 1439 carries the legend that Diogo de Silves discovered the Azores (foram trobades) in 1427 . (I leave in parentheses Waters' claim that they were discovered before in the 14 th century.) The first text referring to the use of a graduated nautical instrument, the quadrant, is dated 1460-2. There is no text that $I$, or the Portuguese historians know of, proving that nautical astronomy was practised with an instrument in that part of the Atlantic between 1427 and 1460-2. Can a historian assume that it was? I think not.

Richey says on page 350 (quoting Waters) that 'the study of early Genoese portulan charts shows that about 1370 Atlantic Moroccan coastlines were delineated true so that the Portuguese discoverers must also by then have known of magnetic variation, one must assume by observations of the North Star [my italics]'. I am afraid that I find that I cannot bring myself to share the conclusions inferred from the evidence provided and most of my Portuguese colleagues feel the same. I cannot speak for Luís de Albuqueque for, alas, he is no longer with us.

On page 35 I Richey writes: 'In the fourteenth century when astronomical navigation was [sic] [my italics and my sic] developed [...] a rule was introduced using the two Guard stars in the Lesser Bear, which rotate anti-clockwise about the North Star, as a form of 